\title{
Short Communication: Antimicrobial Drug Susceptibility of Staphylococcus aureus from Subclinical Bovine Mastitis in Italy
}

\author{
P. Moroni, ${ }^{\star 1}$ G. Pisoni, ${ }^{*}$ M. Antonini, $\dagger$ R. Villa, $\ddagger$ P. Boettcher,$\dagger^{2}$ and S. Carlił \\ *Department of Veterinary Pathology, Hygiene and Public Health, University of Milan, via Celoria 10, 20133 Milan, Italy \\ †Institute of Agricultural Biology and Biotechnology (IBBA), Consiglio Nazionale delle Ricerche (CNR), Milan, Italy \\ ‡Department of Veterinary Sciences and Technologies for Food Safety, University of Milan, via Celoria 10, 20133 Milan, Italy
}

\section{ABSTRACT}

The antimicrobial susceptibility of 68 Staphylococcus aureus isolates collected during 2004 from milk of cows affected by subclinical mastitis was examined. The antimicrobial agents tested were the $\beta$-lactams, penicillin $\mathrm{G}$, amoxicillin, ampicillin, cloxacillin, amoxicillin + clavulanate, cephalonium, and cefoperazone; and other drugs including lincomycin, oxytetracycline, doxycycline, and kanamycin. Minimum inhibitory concentrations recorded show that only certain $\beta$-lactamase-resistant penicillins (specifically cloxacillin) or penicillin combinations (amoxicillin + clavulanate) were consistently effective against Staph. aureus, whereas the other $\beta$-lactam derivatives and drugs from other pharmacological groups were either moderately effective or ineffective. Thus, $\beta$-lactamase-resistant penicillins are to be considered the antimicrobial agents of choice for treatment of bovine mastitis resulting from infection by Staph. aureus.

Key words: Staphylococcus aureus, bovine, minimum inhibitory concentration

Bovine mastitis is the most costly disease to the dairy industry worldwide, with losses estimated at 2 billion dollars per year in the United States alone. These relevant economic losses are attributable to rejected milk, reduced milk quality, early culling, drug costs, veterinary expenses, and increased labor costs (Hoblet et al., 1991; Gruet et al., 2001). The disease is the most frequent reason for the use of antimicrobial agents on dairy farms (Erskine, 2000). Intramammary infection sustained by Staphylococcus aureus may result in clinical or subclinical mastitis and is usually associated with increased SCC. Appropriate treatment of mastitis during the lactation or dry period is an important compo-

Received October 17, 2005.

Accepted February 28, 2006

${ }^{1}$ Corresponding author: paolo.moroni@unimi.it

${ }^{2}$ Current address: Animal Health and Production Section, Joint IAEA/FAO Division, International Atomic Energy Agency, A-1400 Vienna, Austria. nent of any mastitis control program, but the outcome for treatment of mastitis caused by Staph. aureus is variable and the probability of curing the disease is not high, primarily because of poor distribution of the drug in the inflamed udder and the occurrence of staphylococci resistant to antimicrobial agents (Pyörälä and Pyörälä, 1994). During lactation, the cure rate of subclinical mastitis ranges widely, and this variability can be due to the choice of antimicrobial agent as well as to factors associated with the infected cow and the quarter. Therefore, cure is likely not a random event (Schukken et al., 1994). Antimicrobial therapy is a primary tool for controlling staphylococcal mastitis, and antimicrobial susceptibility tests can guide the veterinarian in selecting the most appropriate antimicrobial agent for treatment of IMI by Staph. aureus. However, despite a variety of available antimicrobial agents, success in the treatment of Staph. aureus mastitis, particularly during lactation, is still very low. In fact, Staph. aureus pathogens have many characteristics that make them difficult targets for antimicrobial therapy (Sol et al., 2000). For example, they can penetrate the phagocytic cells and survive inside them. This process shields the pathogens from some of the activity of antimicrobial agents, even with drugs that can penetrate the cells. The objective of the present study was to evaluate the antimicrobial resistance patterns of Staph. aureus isolates collected from IMI in cows from 44 commercial herds in Italy.

Sixty-eight isolates of Staph. aureus taken from individual quarters of 68 cows with subclinical mastitis were used. The isolates were obtained during 2004, from milk samples collected from animals belonging to 42 dairy herds from different regions of Italy. Animals were selected on the basis of having quarter milk SCC greater than 400,000 cells $/ \mathrm{mL}$ but no sign of clinical mastitis. Herds were selected to represent different prevalences of Staph. aureus IMI, ranging from 1 to $100 \%$. The number of isolates for each herd was determined according to the number of lactating animals in each herd: One single isolate was collected from 26 small herds ( $\leq 50$ lactating cows), 2 isolates were collected from 11 medium-sized herds ( $\leq 100$ lactating 
cows), and more than 2 isolates were collected from 5 large herds (>100 lactating cows). All isolates were identified on the basis of morphology, hemolysis pattern, and gram staining. The gram-positive cocci were tested for catalase and coagulase production. The species were identified by biochemical tests and by the API Staph System (BioMérieux, Rome, Italy) and were then stored at $-70^{\circ} \mathrm{C}$ in a nutrient broth enriched with $15 \%$ glycerol.

In the present study, the antibiotics were selected by considering the approved and most frequently used drugs for the treatment of bovine IMI in Italy, even if these drugs were not representative of a particular antibiotic class. The antimicrobial agents selected and provided by manufacturers as powders were penicillin G (PEN), ampicillin (AMP), amoxicillin (AMX), AMX + clavulanate, cloxacillin (CLX), cephalonium (CFL) and cefoperazone (CFP), kanamycin, oxytetracycline, doxycycline, and lincomycin (LIN). The antimicrobial agents were dissolved in suitable solvents to make stock solutions and then diluted in sterile distilled water according to the methods recommended by the Clinical Laboratory Standards Institute (2002). Minimum inhibitory concentration tests were performed according to the microdilution broth method, as recommended by the Clinical Laboratory Standards Institute (2002a), using U-bottomed 96-well microtiter plates. Serial 2fold dilutions of the antimicrobial agents were prepared starting from the stock solution of each drug. The dilution schemes differed according to the antimicrobial agent. Inocula were prepared by diluting an overnight (16 to $18 \mathrm{~h}$ ) Mueller-Hinton broth culture in buffered saline solution to a density of 0.5 on the McFarland turbidity scale and finally diluting it again 40 -fold before testing. The MIC was defined as the lowest concentration of the antimicrobial agent at which the bacterial growth was completely inhibited. A reference strain (Staph. aureus, ATCC 29213) was inoculated as a control in each plate. The MIC data were summarized, calculating the MIC values for which the isolates were equal to or below 50 and $90 \%\left(\mathrm{MIC}_{50}\right.$ and $\mathrm{MIC}_{90}$, respectively), as well as the minimum and maximum MIC values (range). Resistance and susceptibility, for most of the antimicrobial agents tested, were determined according to Clinical Laboratory Standards Institute (2002a) MIC breakpoints for veterinary pathogens. The interpretive criteria, however, were based on MIC data and drug pharmacokinetic data obtained in humans (taken from Clinical Laboratory Standards Institute, 2002b). Staphylococcus aureus was also tested for $\beta$ lactamase production by the nitrocefin test (Cefinase, Becton, Dickinson and Co., Sparks, MD).

Numerous data are available in the literature on the susceptibility to antimicrobial agents of Staph. aureus isolates collected from IMI of dairy cattle (Craven et al., 1986; Watts and Yancey, 1994; Owens et al., 1997; Makovec and Ruegg, 2003; Pengov and Ceru, 2003; Tikofsky et al., 2003). Nevertheless, obtaining continually updated MIC values is important to prevent the use of ineffective antimicrobial drugs. Table 1 reports $\mathrm{MIC}_{50}$ and $\mathrm{MIC}_{90}$ values of the selected antibiotics against the Staph. aureus isolates examined in the present study. All values obtained with the control strain were within the expected ranges for all antimicrobial agents tested. Of the 68 isolates evaluated, none were susceptible to all antibiotics and $64(94 \%)$ were resistant to 3 or more antimicrobial agents. No isolates were resistant to CLX. The $\beta$-lactams (penicillins and cephalosporins) are widely used for intramammary treatment of bovine mastitis, but in the present experiment we observed a very poor activity of $\mathrm{PEN}\left(\mathrm{MIC}_{50}=0.5\right.$ and $\mathrm{MIC}_{90}=$ $2,000 \mu \mathrm{g} / \mathrm{mL}$ ). The $\mathrm{MIC}_{90}$ for PEN reported in previous studies ranged from $<0.06$ to $>100 \mu \mathrm{g} / \mathrm{mL}$ (De Oliveira et al., 2000; Erskine et al., 2004). In our study, 47 isolates (69\%) of Staph. aureus were PEN resistant. This proportion was greater than those reported for comparable studies in Argentina (40\%; Gentilini et al., 2000), the United States (38.4 to 60.9\%; Erskine et al., 2002), and Finland (50\%; Myllys et al., 1998), but was lower than that reported for strains isolated from mammary parenchymas of slaughtered dairy cows in Brazil (75\%; Costa et al., 2000). Similarly, in the penicillin group, AMP and AMX had very poor in vitro activity $\left(\mathrm{MIC}_{50}=2\right.$ and $4 \mu \mathrm{g} / \mathrm{mL}$, and $\mathrm{MIC}_{90}=500$ and $1,000 \mu \mathrm{g} / \mathrm{mL}$, respectively), and 100 and $98.5 \%$ of the isolates were resistant to these respective antimicrobial agents. Results from other studies for $\mathrm{MIC}_{90}$ for AMP differed remarkably from our findings; they ranged from only 0.5 to $4 \mu \mathrm{g} /$ $\mathrm{mL}$ (Watts and Salmon, 1997; De Oliveira et al., 2000). This high level of resistance was probably related to the presence of strong $\beta$-lactamase producers among the tested staphylococcal isolates. The in vitro data confirmed the influence of $\beta$-lactamase production on the microbial susceptibility to $\beta$-lactams in general and to PEN in particular. In fact, the difference between $\mathrm{MIC}_{50}$ and $\mathrm{MIC}_{90}$ values, with reference to PEN, AMP, and AMX, correlates very well with the identification of $28 \beta$-lactamase-producing isolates (58\%). Recalculation of the $\mathrm{MIC}_{90}$ without these strains yielded values of $0.5 \mu \mathrm{g} / \mathrm{mL}$ for PEN and $4 \mu \mathrm{g} / \mathrm{mL}$ for both AMP and AMX. On the other hand, the $\beta$-lactamase-resistant CLX and amoxicillin + clavulanate (a widely used $\beta$ lactamase inhibitor) were both highly effective, with $\mathrm{MIC}_{50}$ of 0.25 and 1 to $0.5 \mu \mathrm{g} / \mathrm{mL}$ and $\mathrm{MIC}_{90}$ of 0.5 and 8 to $4 \mu \mathrm{g} / \mathrm{mL}$, respectively.

The cephalosporins are usually classified into 3 different generations on the basis of their respective antimicrobial spectra. In the present study, CFL and CFP 
Table 1. Antimicrobial susceptibility of 68 isolates of Staphylococcus aureus collected from different animals throughout the lactation ${ }^{1}$

\begin{tabular}{llcllc}
\hline Agent & $\begin{array}{l}\mathrm{MIC}_{50} \\
(\mu \mathrm{g} / \mathrm{mL})\end{array}$ & $\begin{array}{l}\mathrm{MIC}_{90} \\
(\mu \mathrm{g} / \mathrm{mL})\end{array}$ & $\begin{array}{l}\text { Range } \\
(\mu / \mathrm{mL})\end{array}$ & $\begin{array}{l}\text { Breakpoints } \\
(\mu \mathrm{g} / \mathrm{mL})\end{array}$ & $\begin{array}{l}\text { Resistance } \\
(\%)\end{array}$ \\
\hline PEN & 0.5 & 2,000 & 0.007 to $>2,000$ & $\geq 0.25$ & 69.1 \\
AMP & 2 & 500 & 0.25 to $>1,000$ & $\geq 0.5$ & 98.5 \\
AMX & 4 & 1,000 & 0.25 to $>1,000$ & $\geq 0.5$ & 100 \\
AMC & $1 / 0.5^{3}$ & $8 / 4^{3}$ & $0.06 / 0.03$ to $16 / 8$ & $\geq 8 / 4$ & 20.6 \\
CLX & 0.25 & 0.5 & 0.06 to 2 & $\geq 6$ & 16.2 \\
KAN & 8 & 64 & 2 to 250 & $\geq 16$ & 58.8 \\
OXT & 32 & 500 & 1 to $>500$ & $\geq 16$ & - \\
DOX & 8 & 250 & 0.5 to 250 & NA & - \\
CFP & 2 & 16 & 0.5 to $>250$ & NA & - \\
CFL & 0.12 & 2 & 0.06 to 15.6 & NA & - \\
LIN & 4 & 250 & 1 to $>500$ &
\end{tabular}

\footnotetext{
${ }^{1} \mathrm{MIC}_{50}$ and $\mathrm{MIC}_{90}$ are the minimum concentrations of the various antimicrobial agents required to inhibit growth of 50 and $90 \%$ of the isolates tested, respectively. PEN = benzylpenicillin; AMP = ampicillin; AMX = amoxicillin; $\mathrm{AMC}=\mathrm{AMX}$ + clavulanate CLX = cloxacillin; $\mathrm{KAN}=$ kanamycin $; \mathrm{OXT}=$ oxytetracycline; $\mathrm{DOX}=$ doxycycline; CFP = cephoperazone; CFL = cephalonium; and LIN = lincomycin; NA = not available.

${ }^{2}$ Interpretive criteria based on human data.

${ }^{3}$ Amoxicillin/clavulanate concentrations.
}

were included as first-generation (good to excellent activity against gram-positive bacteria but strain-dependent gram negative activity) and third-generation drugs (good to moderate activity against gram-positive bacteria and good to excellent gram negative activity), respectively. Cefoperazone and CFL showed antistaphylococcal activity greater than that of the $\beta$-lactamasesensitive penicillins. Between these 2 drugs, CFL showed greater efficacy than did CFP $\left(\mathrm{MIC}_{50}=0.12 \mathrm{vs}\right.$. $2 \mu \mathrm{g} / \mathrm{mL}$ and $\mathrm{MIC}_{90}=2$ vs. $16 \mu \mathrm{g} / \mathrm{mL}$, respectively). These results may indicate that these agents are resistant to $\beta$-lactamase, which hydrolyzes penicillins. Lincomycin, oxytetracycline, doxycycline, and kanamycin (selected as representative drugs of the lincosamide, tetracycline, and aminoglycoside groups, respectively) had moderate to poor activity against the Staph. aureus isolates tested in the present study, as demonstrated by MIC values ranging from 1 to $>500,1$ to $>500,0.5$ to 250 , and 2 to $250 \mu \mathrm{g} / \mathrm{mL}$, respectively.

The lincosamide antimicrobial agents (e.g., LIN and clindamycin) act by inhibiting RNA-dependent bacterial protein synthesis (Yao and Moellering, 1995). Lincomycin showed an $\mathrm{MIC}_{90}$ of $250 \mu \mathrm{g} / \mathrm{mL}$, and this value was greater than those previously found in other countries. For example, LIN MIC $_{90}$ ranged from 16.0 to 64 $\mu \mathrm{g} / \mathrm{mL}$ for isolates from the United States, Ireland, Iceland, and Germany and from 1.0 to $8.0 \mu \mathrm{g} / \mathrm{mL}$ for isolates from Denmark, England, Norway, Sweden, and Finland (De Oliveira et al., 2000). The LIN MIC M0 $_{0}$ value obtained for the strains tested in this study may be linked with their carriage of the erm gene, which encodes resistance to lincosamides, macrolides, and streptogramine B antimicrobial agents (Leclercq and Courvalin, 1991). Tetracyclines and aminoglycosides are broad-spectrum antibiotics widely used to treat respiratory and other diseases in cattle. Because of this widespread use, tetracycline and aminoglycoside resistance, coded by a wide variety of determinants, was demonstrated by the high $\mathrm{MIC}_{90}$ observed in the present study.

Several factors other than antimicrobial usage can influence the overall susceptibility patterns of mastitis pathogens. Scar tissue in the udders of cattle chronically infected by Staph. aureus often prevents the penetration of antimicrobial agents (De Oliveira et al., 2000). Therefore, the general recommendation is to cull all animals with chronic Staph. aureus IMI. The control of IMI sustained by Staph. aureus should involve the best management practices and selective antimicrobial usage. Unfortunately, most antimicrobial agents used in veterinary medicine still rely on interpretive criteria developed for humans, and the validity of these interpretive criteria for categorizing veterinary pathogens as susceptible or resistant has not been established (Watts and Yancey, 1994). Currently, only pirlimycin and a penicillin-novobiocin combination have had interpretive criteria developed using MIC data generated with mastitis pathogens. Interpretation of antimicrobial susceptibility data for the remaining compounds relies on interpretive criteria developed with human data. The interpretive criteria used for categorizing isolates as susceptible or resistant are based on human data for most of the drugs tested in this study. Thus, the usefulness of susceptibility data is limited to monitoring the percentage of Staph. aureus with MIC above a threshold value, and these values may not be used to predict clinical efficacy. The percentage of resistance data presented in this study was used for comparative purposes but not as an indicator of the actual resistance 
level. The experimental tests performed showed important in vitro activity against the Staph. aureus isolates of the majority of antimicrobial agents currently used in Italy for control of IMI. However, we consider it necessary to develop new interpretive criteria for studying specific mastitis pathogens and for predicting clinical efficacy in all those situations in which, as in cases of mastitis caused by Staph. aureus, scar tissue barriers or other pathological or physiological factors can reduce the in vivo efficacy of the drugs.

\section{ACKNOWLEDGMENTS}

We are thankful to R. Zadoks and L. Tikofsky for technical review of the manuscript.

\section{REFERENCES}

Clinical Laboratory Standards Institute (CLSI). 2002a. Performance Standards for Antimicrobial Disk and Dilution Susceptibility Tests for Bacteria Isolated from Animals: Approved Standard. 2nd ed. Document M31-A. CLSI, Wayne, PA.

Clinical Laboratory Standards Institute (CLSI). 2002b. Performance Standards for Antimicrobial Susceptibility Testing: 12th Informational Supplement. Documents M2-A7 and M7-A5. CLSI, Wayne, PA.

Costa, E. O., N. R. Benites, J. L. Guerra, and P. A. Melville. 2000. Antimicrobial susceptibility of Staphylococcus spp. isolated from mammary parenchymas of slaughtered dairy cows. J. Vet. Med. B: Infect. Dis. Vet. Public Health 47:99-103.

Craven, N., J. C. Anderson, and T. O. Jones. 1986. Antimicrobial drug susceptibility of Staphylococcus aureus isolated from bovine mastitis. Vet. Rec. 118:290-291.

De Oliveira, A. P., J. L. Watts, S. A. Salmon, and F. M. Aarestrup. 2000. Antimicrobial susceptibility of Staphylococcus aureus isolated from bovine mastitis in Europe and the United States. J. Dairy Sci. 83:855-862.

Erskine, R. 2000. Antimicrobial drug use in bovine mastitis. Pages 712-734 in Antimicrobial Therapy in Veterinary Medicine. J. F. Prescott, J. D. Baggot, and R. D. Walker, ed. Iowa State University Press, Ames.

Erskine, R., J. Cullor, M. Schaellibaum, P. Yancey, and A. Zecconi. 2004. Bovine mastitis pathogens and trends in resistance to antibacterial drugs. Page 400-414 in Proc. 43rd National Mastitis Council Mtg. National Mastitis Council, Verona, WI.

Erskine, R. J., R. D. Walker, C. A. Bolin, P. C. Bartlett, and D. G. White. 2002. Trends in antibacterial susceptibility of mastitis pathogens during a seven-year period. J. Dairy Sci. 85:1111-1118.

Gentilini, E., G. Denamiel, P. Llorente, S. Godaly, M. Rebuelto, and O. De Gregorio. 2000. Antimicrobial susceptibility of Staphylococcus aureus isolated from bovine mastitis in Argentina. J. Dairy Sci. 83:1224-1227.

Gruet, P., P. Maincent, X. Berthelot, and V. Kaltsatos. 2001. Bovine mastitis and intramammary drug delivery: Review and perspectives. Adv. Drug Deliv. Rev. 50:245-259.

Hoblet, K. H., G. D. Schnitkey, D. Arbaugh, J. S. Hogan, K. L. Smith, P. S. Schoenberg, D. A. Todhunter, W. D. Hueston, D. E. Pritchard, G. L. Bowman, L. E. Heider, B. L. Brockett, and H. R. Conrad. 1991. Cost associated with selected preventive practices and with episodes of clinical mastitis in nine herds with low somatic cell counts. J. Am. Vet. Med. Assoc. 199:190-196.

Leclercq, R., and P. Courvalin. 1991. Bacterial resistance to macrolide, lincosamide and streptogramin antimicrobial agents by target modification. Antimicrob. Agents Chemother. 35:1267-1272.

Makovec, J. A., and P. L. Ruegg. 2003. Antimicrobial resistance of bacteria isolated from dairy cow milk samples submitted for bacterial culture: 8905 samples (1994-2001). J. Am. Vet. Med. Assoc. 222:1582-1589.

Myllys, V., K. Asplund, E. Brofeldt, V. Hirvela-Koski, T. HonkanenBuzalski, J. Junttila, L. Kulkas, O. Myllykangas, M. Niskanen, H. Saloniemi, M. Sandholm, and T. Saranpaa. 1998. Bovine mastitis in Finland in 1988 and 1995: Changes in prevalence and antimicrobial resistance. Acta Vet. Scand. 39:119-126.

Owens, W. L., C. H. Ray, J. L. Watts, and R. J. Yancey. 1997. Comparison of success of antibiotic therapy during lactation and results of antimicrobial susceptibility test for bovine mastitis. J. Dairy Sci. 80:313-317.

Pengov, A., and S. Ceru. 2003. Antimicrobial drug susceptibility of Staphylococcus aureus strains isolated from bovine and ovine mammary glands. J. Dairy Sci. 86:3157-3163.

Pyörälä, S. H. K., and E. O. Pyörälä. 1994. Efficacy of bovine mastitis therapy during lactation. Proc. XVII Nordic Veterinary Congr., Reykjavik, Iceland. The Icelandic Veterinary Association, Reykjavik.

Schukken, Y. H., B. A. Mallard, J. C. Dekkers, K. E. Leslie, and M. J. Stear. 1994. Genetic impact on the risk of intramammary infections following Staphylococcus aureus challenge. J. Dairy Sci. 77:639-647.

Sol, J., O. C. Sampimon, H. W. Barkema, and Y. H. Schukken. 2000. Factors associated with cure after therapy of clinical mastitis caused by Staphylococcus aureus. J. Dairy Sci. 83:278-284.

Tikofsky, L. L., J. W. Barlow, C. Santisteban, and Y. H. Schukken. 2003. A comparison of antimicrobial susceptibility patterns for Staphylococcus aureus in organic and conventional dairy herds. Microb. Drug Resist. 9(Suppl. 1):S39-S45.

Watts, J. L., and R. L. Yancey. 1994. Identification of veterinary pathogens by use of commercial identification system and new trends in antimicrobial susceptibility testing of veterinary pathogens. Clin. Microbiol. Rev. 7:346-356.

Watts, J. L., and S. A. Salmon. 1997. Activity of selected antimicrobial agents against strains of Staphylococcus aureus isolated from bovine intramammary infections that produce $\beta$-lactamase. $\mathrm{J}$. Dairy Sci. 80:788-791.

Yao, J. D. C., and R. C. Moellering, Jr. 1995. Antibacterial agents. Pages 1281-1307 in Manual of Clinical Microbiology. 6th ed. P. R. Murray, E. J. Baron, M. A. Pfaller, F. C. Tenover, and R. H. Yolken, ed. Am. Soc. Microbiol., Washington, DC. 